\title{
Eleitorado e partidos políticos no Brasil
}

\author{
Denise Paiva \\ Universidade Federal de Goiás \\ Maria do Socorro S. Braga \\ Universidade Federal de São Carlos \\ Jairo Tadeu Pires Pimentel Jr. \\ Universidade de São Paulo
}

\begin{abstract}
Resumo
O artigo verifica em que medida os partidos políticos brasileiros têm sido instrumentos balizadores na formação da preferência eleitoral e na estruturação do voto. Para tanto, explora variáveis do ESEB 2002 e do ESEB 2006 que possibilitam analisar como os eleitores avaliam os partidos enquanto organizações, os vínculos afetivos entre o eleitorado e os partidos e o papel das variáveis socioeconômicas e demográficas na explicação do impacto dos partidos na conformação da escolha eleitoral, representatividade e sentimentos partidários. Os resultados mostram a negativa avaliação dos partidos em 2002 e 2006 e, que, em 2006 a clivagem governo X oposição não mais diferenciou os partidos no quadro da escolha eleitoral.
\end{abstract}

Palavras-chave: partidos políticos; preferência eleitoral; avaliação dos partidos; representatividade

\section{Abstract}

The article verifies in what measure Brazilian parties have been important political tools for the formation of voting preferences. The data from ESEB2002 and ESEB2006 allow to analyse how voters evaluate parties as organizations, the links between parties and voters, and the role of socioeconomic and demographic variables in the explanation of the impact of parties in the formation of political preferences. The results show the negative evaluation of the parties in 2002 and 2006, and that in 2006 the political cleavage between government and opposition did not distinguish parties in the electoral process.

Key-words: Political parties; electoral preference; party evaluation; representation 
PAIVA, D.; BRAGA, M. S. S.; PIMENTEL JR, J. T. P. Eleitorado e Partidos Políticos no Brasil.

Introdução

A existência de uma conexão direta entre partidos políticos e democracia tem sido amplamente difundida e aceita. Como vários estudos têm apontado, os partidos políticos são uma condição necessária, embora não suficiente, para o funcionamento do regime democrático (LA PALOMBARA \& WEINER, 1966; ELDERSVELD, 1982; SARTORI, 1982; ALDRICH, 1995). Sua importância para o funcionamento da democracia pode ser explicada pelas funções que desempenham: estruturam a competição política na arena eleitoral, fornecem aos cidadãos ofertas na agenda pública e opções em termos de políticas públicas, dão inteligibilidade ao sistema político, são atores fundamentais na formação e sustentação de maiorias governantes. Desse modo, as agremiações partidárias são essenciais, tanto por sua atuação no âmbito da representação quanto na arena governamental (MAINWARING,1999; SCHMITTER, 2001).

Este artigo tem como objetivo analisar os partidos sob o ângulo da representação. Pretende-se verificar em que medida os partidos políticos brasileiros têm sido instrumentos balizadores na formação da preferência eleitoral e na estruturação do voto. De maneira mais específica, são analisadas as seguintes variáveis: preferência partidária, grau de representatividade dos partidos, conhecimento dos partidos e confiança nos mesmos vis a vis outras instituições políticas. Estas variáveis permitirão analisar o grau de envolvimento bem como o conhecimento dos partidos políticos brasileiros e a sua avaliação pelo eleitorado.

É oportuno mencionar que o caso brasileiro assume características interessantes e singulares dentre as democracias da terceira onda (HUNTINGTON, 1991). Em primeiro lugar, após o golpe militar que deu origem ao regime autoritário, o sistema partidário então vigente foi extinto e substituído pelo bipartidarismo que, apesar do regime de exceção, funcionou de forma ininterrupta. A partir de 1974, a oposição, representada pelo MDB, foi se fortalecendo e se estruturando, o que levou à estratégia deliberada do regime de minar e fragmentar a oposição por meio da restituição do pluripartidarismo (REIS, 1978; KINZO, 1988; LAMOUNIER, 1988).

Em segundo lugar, durante a redemocratização, um novo sistema partidário foi instituído e novas agremiações partidárias foram criadas, seja por meio de cisões nos partidos herdeiros do capital eleitoral e organizacional acumulado ao longo do bi. partidarismo, seja através de fusões. Ou ainda, a partir de novos grupos sociais organizados durante o processo de transição política (NICOLAU, 1996; BRAGA, 2006). Diante desse quadro, o eleitorado teve, então, que se ajustar a um novo cenário com ampla oferta partidária e buscar compreender e diferenciar perfis ideológicos e programáticos. Em vários outros países, após a democratização, houve a reativação do antigo sistema partidário, o que diminuiu os custos de informação para o eleitorado. 
OPINIÃO PÚBLICA, Campinas, vol. 13, nº 2, Novembro, 2007, p.388-408

Após mais de duas décadas de competição política, é oportuno verificar como os brasileiros avaliam os partidos políticos, em que medida estes são instrumentos importantes na conformação das preferências eleitorais bem como o grau de conhecimento e confiança que desfrutam junto ao eleitorado.

Para levar a cabo esse objetivo, além de analisar as questões relativas à avaliação dos partidos, será também investigado em que medida variáveis socioeconômicas e demográficas explicam algumas diferenças em termos de impacto dos partidos na conformação da escolha eleitoral, representatividade e sentimentos partidários.

\section{Vínculos partidários nas novas democracias}

Existe uma ampla literatura que investiga fatores determinantes e subjacentes às escolhas eleitorais e como estas se relacionam com a formação de preferências ou identidades partidárias (DOWNS 1957; CAMPBELL et al, 1960; CONVERSE 1964; FIORINA, 1981; SARTORI, 1982; POPKIN, 1994). Não se trata aqui de fazer uma revisão das principais abordagens teóricas (sociológica, psicossociológica e escolha racional) sobre o tema, algo que, ademais, já foi feito por diferentes autores (FIGUEIREDO, 1991; CASTRO, 1994; CARREIRÃO, 2002; PIMENTEL JR., 2007).

O importante, para os objetivos deste artigo, é mencionar que as diferentes correntes têm perspectivas de análise distintas acerca de como se estruturam as identidades partidárias e vínculos entre os partidos e o eleitorado. Esses laços podem ser determinados por clivagens (culturais, econômicas ou de classe); predisposições psicológicas e o processo de socialização dos indivíduos e maximização dos interesses e preferências individuais. Não obstante os diferentes mecanismos explicativos, a maioria desses estudos investiga o fenômeno da formação das identidades partidárias em países nos quais a experiência democrática e o processo de formação dos partidos e sistemas partidários tiveram uma trajetória distinta dos países nos quais a experiência democrática é mais recente.

Conforme afirmam Maiwaring e Torcal (2006), os eleitores, os partidos e os sistemas partidários são diferentes nos países que integram as novas democracias. Nesses países, ainda de acordo com os autores, os vínculos entre os partidos e o eleitorado são, em geral, menos ideológicos e programáticos. Desse modo, abordagens que pressupõem fortes lealdades ideológicas entre partidos e o eleitorado, em geral, são insatisfatórias para explicar o fenômeno em tela nas novas democracias. 
PAIVA, D.; BRAGA, M. S. S.; PIMENTEL JR, J. T. P. Eleitorado e Partidos Políticos no Brasil.

No mesmo diapasão, Kinzo (2005) assevera que, no Brasil, a estrutura de incentivos sob a qual se desenvolve a competição partidária torna difícil para o eleitor não somente distinguir os competidores como também criar lealdades partidárias. Esse estado de coisas explicaria, segundo a autora, por que as taxas de preferência partidária não têm aumentado nos anos mais recentes.

Nos últimos anos, a ciência política brasileira tem desenvolvido uma ampla literatura sobre o funcionamento dos partidos e do sistema partidário brasileiro sob diferentes perspectivas. Em sua maioria, tais estudos têm demonstrado uma visão positiva acerca dos mesmos no que diz respeito à sua atuação na arena governamental ou em termos de estabilidade da competição eleitoral (MENEGUELLO, 1998; LIMONGI e FIGUEIREDO, 1999, 2002; PAIVA e BOHN, 2006, 2007; BRAGA, 2006).

Neste artigo, verificamos em que medida esse mesmo desempenho satisfatório se repete quando os partidos políticos são analisados do ponto de vista de sua clientela, isto é, o eleitorado. Essa é uma dimensão importante, pois permite verificar se questões programáticas oriundas da oferta partidária são elementos determinantes na conformação da escolha eleitoral. Em segundo lugar, torna possível mensurar o grau de confiança e legitimidade depositado nos partidos políticos e as implicações desses achados.

A estruturação da competição eleitoral é tida como uma das atividades primordiais dos agentes partidários em uma democracia representativa. É a atividade que confere aos partidos políticos um papel distinto em relação a outros atores políticos, dado que Ihes permite recrutar e nomear candidatos a diferentes funções, oferecer aos cidadãos uma "integração simbólica" acerca da agenda pública, issues, consensos e fundamentos de uma sociedade democrática (SCHMITTER, 2001).

No entanto, alguns estudos têm chamado atenção para o declínio dos partidos políticos quanto à sua capacidade de estruturação do voto. Essa redução resultaria de uma combinação de fatores individuais e sistêmicos (DALTON, MACALLISTER \& WATTENBERG, 2003). Dentre esses fatores, estaria o desenvolvimento dos meios de comunicação, particularmente da mídia, como principais fontes de informações, tirando dos partidos o papel de orientadores dos cidadãos na decisão do voto. Ademais, destaca-se a dificuldade dos partidos políticos de se adaptarem e incorporarem a seu perfil programático o advento dos valores pós-materialistas e as mudanças normativas e socias ocorridas no final do século XX (LIPSET, 2001; DIAMOND \& GUNTHER, 2001).

Dentro desse contexto crítico da atuação dos partidos na esfera da representação, este artigo verifica quais são os sentimentos do eleitorado sobre os atuais partidos que conformam o sistema partidário brasileiro. 
OPINIÃO PÚBLICA, Campinas, vol. 13, n², Novembro, 2007, p.388-408

\section{Laços partidários no Brasil}

Depois de mais de duas décadas, período em que ocorreram treze disputas eleitorais, é importante verificar a visão do eleitorado brasileiro sobre os partidos. Esta questão está analisada sob dois aspectos. Primeiro, verificamos como os eleitores avaliam os partidos enquanto organizações; em seguida, investigamos se há ou não vínculos afetivos (emocionais) entre o eleitorado e os partidos. Analisados esses aspectos e identificado o grau de estruturação das decisões eleitorais, averiguamos que tipos de variáveis explicam o grau de estruturação do voto.

Utilizamos três variáveis para mensurar as percepções partidárias: uma cognitiva, baseada na idéia de representação, e duas variáveis mais afetivas, a primeira perguntando se existe algum partido que os eleitores gostam, e a segunda requisita aos eleitores que expressem o quanto gostam dos seis maiores partidos políticos: PT, PSDB, PMDB, PDT, PFL e PTB ${ }^{1}$. A finalidade dessa mensuração é detectar tanto o grau de estruturação do voto quanto possíveis alterações nas predisposições afetivas do eleitorado.

A Tabela 1.1 mostra que, de acordo com os dado do ESEB 2002, um pouco menos de $40 \%$ do eleitorado identificavam algum partido político como representativo de sua maneira de pensar, enquanto $48 \%$ indicavam gostar de algum partido. Apesar da tendência observada pela bibliografia de diminuição da relevância dos partidos na estruturação do voto em vários países, no Brasil existe uma parcela do eleitorado que é influenciada pelos partidos em sua decisão na hora de votar, o que demonstra que eles, em alguma medida, contribuem para estruturar o voto.

No entanto, em 2006, houve uma acentuada queda de 11 pontos percentuais em relação a 2002 no número de eleitores que declararam sentir-se representados por algum partido político (ver Tabela 1.1). Da mesma forma, observou-se uma queda no percentual de eleitores que disseram gostar de algum partido. Enquanto em 2002 o percentual era de 48\%, em 2006 esse passou a 33\%, um declínio de 15\% (Tabela 1.2).

\footnotetext{
${ }^{1} \mathrm{~A}$ avaliação é feita segundo uma escala que varia de 0 a 10, onde 0 representa "não gosta" e 10 "gosta muito".
} 
PAIVA, D.; BRAGA, M. S. S.; PIMENTEL JR, J. T. P. Eleitorado e Partidos Políticos no Brasil.

Tabela1.1

\begin{tabular}{|c|c|c|c|}
\hline \multicolumn{4}{|c|}{$\begin{array}{c}\text { Algum partido político representa sua } \\
\text { maneira de pensar (\%) }\end{array}$} \\
\hline & 2002 & 2006 & Saldo \\
\hline Não & 56 & 67 & 11 \\
\hline Sim & 39 & 28 & -11 \\
\hline NS/NR & 5 & 5 & 0 \\
\hline
\end{tabular}

Fonte: ESEB, 2002 e 2006.
Tabela 1.2

\begin{tabular}{|c|c|c|c|}
\hline \multicolumn{4}{|c|}{ Gosta de algum partido político (\%) } \\
\hline & 2002 & 2006 & Saldo \\
\hline Não & 50 & 64 & 14 \\
\hline Sim & 48 & 33 & -15 \\
\hline NS/NR & 2 & 3 & 1 \\
\hline
\end{tabular}

Nas Tabelas 1.3 e 1.4 podem ser observadas as tendências para os diferentes partidos políticos. Segundo os dados, o PT teve perdas de eleitores tanto no quesito "representa sua maneira de pensar" (menos 5\%) quanto no quesito "partido que gosta" (menos 4\%). O PMDB também perdeu $4 \%$ de eleitores na segunda questão (Tabela 1.4), já o PFL perdeu 3\%. Além disso, o PFL perdeu também $2 \%$ de eleitores que diziam tê-lo como "partido que melhor representava sua maneira de pensar". Os demais partidos não demonstraram nenhuma queda significativa nos itens analisados.

Tabela 1.3

\begin{tabular}{|l|c|c|c|}
\hline \multicolumn{5}{|c|}{$\begin{array}{c}\text { Partido que melhor representa sua } \\
\text { maneira de pensar (\%) }\end{array}$} \\
\hline & 2002 & 2006 & Saldo \\
\hline PT & 23 & 18 & -5 \\
\hline PMDB & 4 & 4 & 0 \\
\hline PSDB & 4 & 4 & 0 \\
\hline PFL & 2 & 0 & -2 \\
\hline PDT & 1 & 1 & 0 \\
\hline PTB & 0 & 1 & 0 \\
\hline Outros & 3 & 2 & -1 \\
\hline Nomes & 2 & - & - \\
\hline NSA & 61 & 72 & 11 \\
\hline
\end{tabular}

Fonte: ESEB, 2002 e 2006.
Tabela 1.4

\begin{tabular}{|c|c|c|}
\hline \multicolumn{3}{|c|}{ Partido que Gosta (\%) } \\
\hline 2002 & 2006 & Saldo \\
\hline 26 & 22 & -4 \\
\hline 7 & 3 & -4 \\
\hline 5 & 4 & 0 \\
\hline 3 & 1 & -3 \\
\hline 1 & 1 & 0 \\
\hline 1 & 1 & 0 \\
\hline 4 & 1 & -3 \\
\hline 2 & - & - \\
\hline 52 & 67 & 15 \\
\hline
\end{tabular}


OPINIÃO PÚBLICA, Campinas, vol. 13, n², Novembro, 2007, p.388-408

A escala de sentimentos também demonstra diminuição quanto à preferência do eleitorado por algum partido. Como é mostrado nas Tabelas 2.1, 2.2 e 2.3, essa predisposição foi observada em relação a todos os partidos. O partido que mais perdeu foi o PMDB: sua nota média de 4,74 passou para 3,09, com uma perda de -1,65; e de $18 \%$ dos eleitores que tinham um sentimento partidário entre 7 e 10 pelo PMDB em 2002, houve uma queda para 7\% em 2006.

O PT aparece em segundo lugar como o partido que mais perdeu apelo afetivo junto ao eleitorado. Em 2002, a nota média na escala de sentimentos partidários era 5,96 e passou para 4,86 em 2006, uma perda de 1,28. Em termos percentuais, em 2002, 48\% dos eleitores expressavam um sentimento entre 7 e 10 pelo PT; em 2006 esse percentual caiu para 32\%, uma queda de $16 \%$.

O PTB, apesar de não ter apresentado uma queda grande em termos de média, foi o segundo partido que mais caiu em termos percentuais (16\%). O PSDB e o PFL também apresentaram uma considerável queda em termos percentuais. Em 2002, 26\% e 19\% expressavam um sentimento entre 7 e 10 pelo PSDB e pelo PFL, respectivamente, já em 2006 esses percentuais passaram a 7\% e 6\%, uma queda de $8 \%$ para o PFL e 7\% para o PSDB. O PDT também teve uma acentuada queda de $10 \%$ na categoria "sentimentos" entre 7 e 10.

Tabela 2.1

\begin{tabular}{|c|c|c|c|c|c|}
\cline { 2 - 6 } \multicolumn{1}{c|}{} & \multicolumn{5}{|c|}{ Gosto Partidário 2002 } \\
\cline { 2 - 6 } & 0 a & 4 a & 7 a & NS/ & Nota \\
& 3 & 6 & 10 & NR \\
$(\%)$ & $(\%)$ & $\begin{array}{c}\text { média } \\
(\%)\end{array}$ & \\
\hline PT & 26 & 19 & 48 & 8 & 5,96 \\
\hline PMDB & 39 & 23 & 18 & 20 & 4,74 \\
\hline PSDB & 39 & 23 & 13 & 26 & 4,21 \\
\hline PFL & 36 & 26 & 20 & 19 & 3,85 \\
\hline PTB & 32 & 25 & 28 & 15 & 3,73 \\
\hline PDT & 37 & 24 & 13 & 27 & 3,62 \\
\hline
\end{tabular}

Tabela 2.2

\begin{tabular}{|c|c|c|c|c|}
\hline \multicolumn{5}{|c|}{ Gosto Partidário 2006} \\
\hline $\begin{array}{c}0 \text { a } \\
3 \\
(\%)\end{array}$ & $\begin{array}{c}4 a \\
6 \\
(\%)\end{array}$ & $\begin{array}{c}7 \text { a } \\
10 \\
(\%)\end{array}$ & $\begin{array}{l}\text { NS/ } \\
\text { NR } \\
(\%)\end{array}$ & $\begin{array}{l}\text { Nota } \\
\text { média }\end{array}$ \\
\hline 35 & 27 & 32 & 6 & 4,68 \\
\hline 46 & 32 & 7 & 16 & 3,09 \\
\hline 42 & 34 & 6 & 18 & 3,51 \\
\hline 40 & 34 & 12 & 14 & 2,95 \\
\hline 38 & 35 & 13 & 14 & 3,59 \\
\hline 43 & 32 & 6 & 18 & 2,94 \\
\hline
\end{tabular}

Tabela 2.3

\begin{tabular}{|c|c|c|c|}
\hline \multicolumn{4}{|c|}{ Saldo } \\
\hline $0 \mathrm{a}$ & $4 \mathrm{a}$ & $7 \mathrm{a}$ & Nota \\
3 & 6 & 10 & $\begin{array}{c}\text { média } \\
(\%)\end{array}$ \\
$(\%)$ & $\%)$ & \\
\hline 9 & 8 & .16 & $-1,28$ \\
\hline 6 & 8 & .11 & $-1,65$ \\
\hline 3 & 12 & .7 & $.0,70$ \\
\hline 4 & 8 & .8 & $.0,90$ \\
\hline 6 & 10 & .15 & $.0,14$ \\
\hline 7 & 8 & .7 & $.0,68$ \\
\hline
\end{tabular}

Fonte: ESEB, 2002 e 2006.

Esses dados revelam, portanto, a diminuição nos sentimentos positivos do eleitorado em relação aos partidos no período 2002-2006, seguindo, assim, tendência já apontada pelos estudos sobre o tema (KINZO, 2005). Esse declínio parece não estar relacionado a um ou dois partidos (apesar de PT e PMDB apresentarem maior tendência de queda), mas expressa um descontentamento mais geral de parte considerável dos eleitores em relação à instituição partidária. 
PAIVA, D.; BRAGA, M. S. S.; PIMENTEL JR, J. T. P. Eleitorado e Partidos Políticos no Brasil.

Uma explicação possível para tal quadro pode estar relacionada com o histórico atual do Congresso e com os escândalos de corrupção envolvendo boa parte dos partidos políticos. Um desses escândalos ficou conhecido como "mensalão". Esse escândalo irrompeu em junho de 2005 através de uma fita de vídeo que mostrou o ex-funcionário dos Correios, Maurício Marinho, negociando propina com empresários interessados em uma licitação. Nesse vídeo, Marinho dizia ter respaldo do deputado Roberto Jefferson (PTB).

Por sua vez, Roberto Jefferson acusou deputados da base governista de receberem um "mensalão" de 30 mil reais do tesoureiro do PT, Delúbio Soares. Segundo Jefferson ${ }^{2}$ afirmou à época ${ }^{3}$, o dinheiro do mensalão vinha de empresas estatais e privadas e era entregue aos parlamentares por operadores como o publicitário Marcos Valério e o então líder do PP na Câmara José Janene. A partir disso, foi deflagrada a "CPI dos Correios" para investigar o envolvimento de empresas estatais para alimentar os recursos do "mensalão".

Essas denúncias atingiram diretamente a cúpula do PT e nomes como o chefe da Casa Civil José Dirceu, o deputado José Genoíno, o secretário geral do PT, Sílvio Pereira (além do já mencionado Delúbio Soares). Os desgastes dessas denúncias fizeram Dirceu, até então principal figura do governo Lula, e José Genoíno, umas das principais lideranças da história do PT, abandonarem seus cargos. Essa crise de corrupção ajuda a explicar sobretudo por que o PT, partido que vinha crescendo junto ao eleitorado desde sua fundação, teve uma queda tão acentuada em termos de identidade partidária.

Nas Tabelas 3.1 e 3.2 aparece, de maneira indireta, o impacto desses eventos na legislatura 2002-2006. Nelas se encontram avaliações de várias instituições, inclusive do Congresso. Observa-se que, em relação a 2002, nenhuma instituição teve perdas significativas na avaliação dos eleitores, algumas, inclusive foram mais bem avaliadas. Entretanto, a avaliação do Congresso e dos partidos piorou. Um significativo agravante na história dos já depreciados políticos brasileiros.

\footnotetext{
2 Roberto Jefferson teve seu mandato cassado pelo Congresso por quebra do decoro parlamentar por não conseguir provar suas denúncia. Ironicamente, a chamada "CPI do mensalão" concluiu posteriormente que esse de fato existiu. Segundo o relatório dessa CPI: "houve recebimento de vantagens indevidas por parlamentares e dirigentes partidários com peridiocidade variável, mas constante, em 2002 e 2003. Chame-se isso mensalão quem quiser; chame-se isso quinzenão quem quiser; chame-se se isso semanão quem quiser". "Por 23 assinaturas, CPI do mensalão chega ao fim". Folha de São Paulo, 18/11/2005.

3 O caso do Mensalão teve início com a denúncia de Roberto Jefferson em entrevista concedida ao jornal Folha de São Paulo em 02/07/2005.
} 
Tabela 3.1

\begin{tabular}{|c|c|c|c|c|}
\cline { 2 - 5 } \multicolumn{1}{c|}{} & \multicolumn{4}{c|}{$2002(\%)$} \\
\hline $\begin{array}{c}\text { Instituição/ } \\
\text { Avaliação }\end{array}$ & $\begin{array}{c}\text { Péssima/ } \\
\text { Ruim }\end{array}$ & Regular & $\begin{array}{c}\text { Boa/ } \\
\text { Otima }\end{array}$ & $\begin{array}{c}\text { NS/ } \\
\text { NR }\end{array}$ \\
\hline Igreja católica & 12 & 2 & 83 & 4 \\
\hline Polícia & 40 & 6 & 52 & 2 \\
\hline $\begin{array}{c}\text { Governo } \\
\text { federal }\end{array}$ & 40 & 7 & 50 & 4 \\
\hline Justiça & 51 & 6 & 40 & 3 \\
\hline $\begin{array}{c}\text { Grandes } \\
\text { empresas }\end{array}$ & 25 & 6 & 61 & 8 \\
\hline $\begin{array}{c}\text { Partidos } \\
\text { políticos }\end{array}$ & 53 & 7 & 33 & 7 \\
\hline Congresso & 49 & 6 & 34 & 11 \\
\hline Militares & 28 & 6 & 56 & 9 \\
\hline Rede Globo & 16 & 4 & 76 & 5 \\
\hline $\begin{array}{c}\text { Outras } \\
\text { emissoras }\end{array}$ & 15 & 6 & 71 & 7 \\
\hline
\end{tabular}

Fonte: ESEB, 2002 e 2006.
Tabela 3.2

\begin{tabular}{|c|c|c|c|}
\hline \multicolumn{5}{|c|}{$2006(\%)$} \\
$\begin{array}{c}\text { Péssima/ } \\
\text { Ruim }\end{array}$ & Regular & $\begin{array}{c}\text { Boa/ } \\
\text { Otima }\end{array}$ & $\begin{array}{c}\text { NS/ } \\
\text { NR }\end{array}$ \\
\hline 8 & 8 & 82 & 3 \\
\hline 33 & 15 & 51 & 1 \\
\hline 33 & 14 & 52 & 1 \\
\hline 44 & 14 & 41 & 1 \\
\hline 21 & 13 & 64 & 2 \\
\hline 58 & 14 & 26 & 3 \\
\hline 57 & 14 & 26 & 3 \\
\hline 29 & 14 & 55 & 2 \\
\hline 10 & 8 & 81 & 1 \\
\hline 9 & 10 & 80 & 1 \\
\hline
\end{tabular}

\section{Variáveis explicativas do grau de estruturação do voto}

A seguir, este artigo busca identificar quais variáveis explicam melhor o grau de estruturação do voto. Seguindo orientações defendidas pela teoria do desenvolvimento político em contraste com teorias culturalistas, será avaliado o impacto de variáveis socioeconômicas e aquelas relacionadas às atitudes políticas dos eleitores encontradas nos dados do ESEB de 2006.

Na Tabela 4.1, é possível ver que o impacto de variáveis socioeconômicas e demográficas para explicar esse grau de orientação dos cidadãos na decisão do voto é praticamente inexistente. Os poucos valores de correlação gama ${ }^{4}$

\footnotetext{
4 Segundo Babbie (2005), o índice de correlação gama é o mais adequado para se tratar variáveis ordinais. Como as variáveis que mensuram as emoções são ordinais, esse índice é utilizado com o intuito de analisar a força de associação entre essas variáveis e as variáveis dependentes. Os valores de correlação gama variam de $\cdot 1$ a 1 , sendo que, quanto mais próximo de $\cdot 1$, maior a relação inversamente proporcional. De outro lado, quanto mais o valor se aproxima de 1, maior a relação diretamente proporcional.
} 
PAIVA, D.; BRAGA, M. S. S.; PIMENTEL JR, J. T. P. Eleitorado e Partidos Políticos no Brasil.

significantes demonstram que os eleitores do sul tenderam mais a declarar que havia um partido que representava sua forma de pensar $(0,202)$, enquanto os eleitores de regiões metropolitanas tenderam mais a dizer que gostavam de algum partido $(0,295)$. Eleitores do sexo masculino tenderam mais a afirmar tanto que existiria um partido que gostavam quanto que existia um partido que representava sua forma de pensar $(0,157$ e 0,235, respectivamente).

Surpreendentemente, o nível de escolaridade, considerado pela literatura a principal variável explicativa da existência de preferência partidária no eleitorado (CASTRO,1994; CARREIRÃO \& KINZO, 2004; KINZO, 2005), não demonstrou correlação significativa para explicar as predisposições do eleitorado em relação aos partidos.

Tabela 4.1 - Correlação Gama entre variáveis

\begin{tabular}{|l|c|c|}
\hline REGIÃO & REPRESENTAÇÃo & $\begin{array}{c}\text { GOSTA DE ALGUM } \\
\text { PARTIDO }\end{array}$ \\
\hline Nordeste & $-0,003$ & 0,017 \\
\hline Norte/Centro Oeste & 0,057 & $-0,032$ \\
\hline Sudeste & $-0,136$ & $-0,017$ \\
\hline Sul & $0,202^{* *}$ & 0,034 \\
\hline Capital & $-0,100$ & $-0,104$ \\
\hline Interior & 0,011 & $-0,038$ \\
\hline Região metropoliana & 0,180 & $0,295^{*}$ \\
\hline Nível de escolaridade & 0,016 & $-0,024$ \\
\hline Faixa etária & 0,041 & 0,074 \\
\hline Sexo - homem & $0,235^{*}$ & $0,157^{* *}$ \\
\hline Classe social & $-0,066$ & 0,013 \\
\hline Faixa de renda familiar & 0,059 & $-0,001$ \\
\hline Faixa de renda pessoal & 0,016 & $-0,040$ \\
\hline
\end{tabular}

Fonte: ESEB, 2002 e 2006. ${ }^{*}$ sig. $<0,01 * *$ sig. $<0,05$

Já no que diz respeito às variáveis atitudinais, há informações importantes para explicar o grau de estruturação observado. As variáveis atitudinais buscam mensurar elementos de uma cultura política democrática, demonstrando como os eleitores avaliam a democracia, a atuação dos partidos, e a disposição em participar do processo eleitoral.

A noção de uma cultura política democrática ancora-se no clássico livro de Almond e Verba (1963), The Civic Culture. Nele, os autores defendem a idéia de que 
OPINIÃO PÚBLICA, Campinas, vol. 13, n², Novembro, 2007, p.388-408

a apreensão subjetiva dos indivíduos em relação à estrutura política é um fator importante para a estabilidade do regime democrático e que através das orientações subjetivas dos cidadãos seria possível mensurar o grau de democratização de um sistema político. Nesse sentido, uma cultura política democrática seria aquela em que os cidadãos conhecem bem suas instituições políticas, possuem uma orientação afetiva em relação a elas e as valorizam. Segundo essa abordagem, a orientação positiva em relação às instituições políticas estimularia os indivíduos a participarem do universo político e utilizarem essas instituições como balizadoras de seu pensamento. Dessa forma, a orientação afetiva pelos partidos significaria uma internalização normativa dessa instituição política no eleitorado, ou seja, os eleitores apreenderiam a importância dessa instituição para o funcionamento da democracia e, por conseguinte, utilizariam os partidos para entender os eventos presentes dentro da esfera política.

$\mathrm{Na}$ Tabela 4.2, encontram-se valores de correlação gamma entre essas variáveis atitudinais e a idéia de representação e gosto por algum partido. Tal como pode ser observado, essas variáveis atitudinais possuem correlação positiva e significante com as variáveis que mensuram as orientações afetivas pelos partidos no eleitorado. A valorização da democracia, a participação eleitoral e a avaliação positiva dos partidos mostram que os eleitores indicam que um dos partidos representa sua forma de pensar e por que gostam de algum partido. Isso denota que a cultura política democrática é fundamental para haver predisposições afetivas pelos partidos no eleitorado.

Tabela 4.2 - Correlação Gamma entre variáveis

\begin{tabular}{|l|c|c|}
\cline { 2 - 3 } \multicolumn{1}{c|}{} & Representação & $\begin{array}{c}\text { Gosta de algum } \\
\text { partido }\end{array}$ \\
\hline Se o voto não fosse obrigatório o(a) Sr(a) votaria? sim & $0,353^{*}$ & $0,231^{*}$ \\
\hline $\begin{array}{l}\text { O que é melhor, um presidente da república que seja } \\
\text { identificado com o partido }\end{array}$ & $0,303^{*}$ & $0,270^{* *}$ \\
\hline Faz diferença quem governa & $0,137^{*}$ & $0,371^{*}$ \\
\hline Influência do Voto & $0,224^{*}$ & $-0,164^{*}$ \\
\hline Avaliação positiva da atuação dos partidos & $0,187^{*}$ & $-0,181^{*}$ \\
\hline Satisfação com a democracia & $0,321^{*}$ & $-0,260^{*}$ \\
\hline Democracia melhor forma de governo & $0,308^{*}$ & $-0,325^{*}$ \\
\hline
\end{tabular}

Fonte: ESEB, 2002 e 2006. * sig.<0,01** sig.<0,05 
PAIVA, D.; BRAGA, M. S. S.; PIMENTEL JR, J. T. P. Eleitorado e Partidos Políticos no Brasil.

Os partidos se diferenciam para o eleitorado?

Na ampla literatura sobre partidos políticos, sistema partidário e comportamento eleitoral, uma das funções atribuídas aos partidos políticos é a de servir de referência, ou atalho de informação, para a tomada de decisão dos eleitores (POPKIN, 1991; DIAMOND \& GUNTHER, 2001; MAINWARING \& TORCAL, 2005; KINZO, 2005). Nesse sentido, a questão a ser examinada nesta seção é se, apesar da queda no partidarismo observada anteriormente, os partidos se diferenciam para o eleitorado.

Para responder a essa questão, usamos a escala de sentimentos partidários. Esta escala oferece uma forma muito mais abrangente para entender como os partidos estão presentes no eleitorado. Diferentemente das outras formas de mensuração do partidarismo, nas quais as preferências são expressas de maneira espontânea e única, essa escala requisita ao entrevistado que se posicione em relação a uma variedade de partidos, o que significa dizer que os eleitores podem demonstrar disposições positivas ou negativas por mais de uma legenda ${ }^{5}$. O resultado desse tipo de estímulo é que o número de missing cases é muito mais baixo do que aquele verificado quando se utilizam perguntas que oferecem estímulos de respostas únicas e espontâneas sobre o partidarismo (PIMENTEL JR., 2007).

Como a escala de sentimentos requisita que os eleitores se posicionem em relação aos seis maiores partidos, é possível que os eleitores se posicionem favoravelmente em relação a todos eles ou, de outro modo, em relação a nenhum deles. Espera-se, porém, que, se os partidos de fato estruturam as preferências políticas, os eleitores se posicionem afetivamente favorável a um deles e contrário aos demais.

Nas Tabelas 5.1 e 5.2 encontram-se as correlações de Pearson ${ }^{6}$ entre os sentimentos partidários dos eleitores e os vários partidos tanto em 2002 quanto em 2006. Para 2002, observou-se a correlação positiva entre os sentimentos dos eleitores e o PT, PDT e PTB, denotando que os eleitores que gostavam de um desses partidos tendiam a gostar dos outros também. Entretanto, observou-se uma correlação negativa, mesmo que muito fraca, entre os sentimentos dos eleitores ao PT em relação aos sentimentos pelo PSDB, PFL, PMDB. As demais correlações demonstraram que os eleitores tendem a gostar de todos os partidos.

\footnotetext{
${ }^{5}$ A pergunta feita para mensurar a disposição afetiva dos eleitores é a seguinte: "Por favor, use uma nota de 0 a 10 para indicar o quanto o(a) Sr(a). gosta do partido que eu vou mencionar."

6 O coeficiente de correlação de Pearson é o método indicado para descrever, através de um único número, o grau de associação entre duas variáveis escalares.
} 
OPINIÃO PÚBLICA, Campinas, vol. 13, n², Novembro, 2007, p.388-408

Tabela 5.1 - Correlação de Pearson

2002

\begin{tabular}{|c|c|c|c|c|c|c|}
\cline { 2 - 7 } \multicolumn{1}{c|}{} & PT & PDT & PSDB & PFL & PMDB & PTB \\
\hline PT & 1 & & & & & \\
\hline PDT & $0,355^{* *}$ & 1 & & & & \\
\hline PSDB & $-0,083^{* *}$ & $0,222^{* *}$ & 1 & & & \\
\hline PFL & $-0,053^{* *}$ & $0,199^{* *}$ & $0,427^{* *}$ & 1 & & \\
\hline PMDB & $-0,059^{* *}$ & $0,163^{* *}$ & $0,441^{* *}$ & $0,362^{* *}$ & 1 & \\
\hline PTB & $0,109^{* *}$ & $0,431^{* *}$ & $0,361^{* *}$ & $0,341^{* *}$ & $0,353^{* *}$ & 1 \\
\hline
\end{tabular}

Fonte: ESEB, 2002 e 2006.

Esses dados denotam que, em 2002, ainda havia uma diferenciação do PT em relação aos partidos governistas da época. Entretanto, em 2006, essa diferenciação parece ter acabado. Tal como mostra a Tabela 5.2, existia uma correlação positiva entre os sentimentos dos eleitores em relação a todos os partidos, denotando a não diferenciação dos partidos entre o eleitorado.

Uma das explicações para essa homogeneização está relacionada com a chegada do PT no governo federal ao lado de uma coalizão governamental bastante heterogênea. Outro elemento a ser acrescentado é o próprio desgaste oriundo do fato de o partido estar no governo e ser avaliado de forma mais sistemática por suas ações (ou omissões) resultantes dessa condição. Além disso, à medida que o PT foi tendo possibilidades reais de ganhar a disputa eleitoral para a Presidência da República, foi ampliando tanto o leque de partidos que vieram compor sua coligação eleitoral quanto seu apelo eleitoral entre os segmentos do eleitorado situados mais ao centro bem como à direita do aspecto político-ideológico, redundando na perda da radicalização política em que esse partido se encontrava quando na oposição. Com isso, o PT que, ao se constituir, ao longo dos anos 90, como o partido de esquerda mais importante do sistema político brasileiro bem como da América do Sul, se tornou um dos atores partidários cruciais na estruturação e nacionalização do sistema partidário brasileiro e, depois de 2006, teve essa função cada vez mais reduzida (BRAGA, 2006). 
PAIVA, D.; BRAGA, M. S. S.; PIMENTEL JR, J. T. P. Eleitorado e Partidos Políticos no Brasil.

Tabela 5.2 - Correlação de Pearson

2006

\begin{tabular}{|c|c|c|c|c|c|c|}
\cline { 2 - 7 } \multicolumn{1}{c|}{} & PT & PDT & PSDB & PFL & PMDB & PTB \\
\hline PT & 1 & & & & & \\
\hline PDT & $0,437^{* *}$ & 1 & & & & \\
\hline PSDB & $0,123^{* *}$ & $0,591^{* *}$ & 1 & & & \\
\hline PFL & $0,301^{* *}$ & $0,733^{* *}$ & $0,708^{* *}$ & 1 & & \\
\hline PMDB & $0,304^{* *}$ & $0,686^{* *}$ & $0,636^{* *}$ & $0,700^{* *}$ & 1 & \\
\hline PTB & $0,374^{* *}$ & $0,816^{* *}$ & $0,656^{* *}$ & $0,762^{* *}$ & $0,712^{* *}$ & 1 \\
\hline
\end{tabular}

Fonte: ESEB, 2002 e 2006.

Outra forma que permite verificar a diferenciação (ou melhor, a falta de diferenciação) dos partidos no eleitorado é a análise fatorial. Esse tipo de método estatístico multivariado busca definir a existência de elementos latentes (ou seja, fatores) em uma matriz de dados através da análise de covariância, de forma a descobrir quais variáveis estão mensurando uma mesma coisa (PEREIRA, 2004). 0 objetivo desse tipo de análise é encontrar uma combinação linear das variáveis originais que estejam altamente correlacionadas entre si e que, por conta disso, formem um fator.

A aplicação desse tipo de análise segue a seguinte lógica: se os partidos se diferenciam no eleitorado, serão obtidos tantos fatores quanto for o número de partidos requisitado aos eleitores expressarem seus sentimentos; ao contrário, quanto menor essa diferenciação, menor o número de fatores, sendo que a existência de apenas um fator representa que não há qualquer diferenciação.

As Tabelas 6.1 e 6.2 apresentam a análise fatorial dos sentimentos dos eleitores em relação aos partidos em 2002 e em 2006 . Os valores acima de 0,5 (marcados em negrito) denotam que a variável pertence a um determinado componente fatorial. Observa-se a existência de dois componentes fatoriais dos sentimentos dos eleitores em relação aos partidos em 2002; o primeiro componente apresentava o PSDB, o PFL, o PMDB e o PTB, enquanto o segundo componente apresentava o PT e o PDT. Isso significa dizer que, por um lado, os

\footnotetext{
7 O método de análise fatorial adotado foi o de componentes principais e a rotação varimax. A análise das componentes principais busca explicar a estrutura da variância e da covariância através de poucas combinações lineares das variáveis originais. Segundo Pereira (2004), nessa forma de análise "primeiro identifica-se a dimensão que melhor distingue os objetos, em seguida, a função ortogonal a ela; não estando os objetos perfeitamente discriminados, um novo componente discriminador será buscado, a função ortogonal derivada e assim por diante" (PEREIRA, 200, p.118). Já a rotação varimax, segundo Hair et al (2005) é um dos métodos de rotação ortogonal (onde os eixos dos fatores são mantidos a $90^{\circ}$ e são mantidos não correlacionados) mais populares. Ela se caracteriza pelo fato de oferecer uma solução mais simples das colunas de matriz fatorial e apresentar uma separação mais clara dos fatores. Ela assim o faz através da geração de cargas fatoriais mais próximas de 1 , indicando uma clara associação positiva entre as variáveis, ou mais próximas de 0 , sinalizando a ausência de associação.
} 
OPINIÃO PÚBLICA, Campinas, vol. 13, n², Novembro, 2007, p.388-408

sentimentos pelos partidos presentes no primeiro componente mensuravam uma mesma coisa e, portanto, esses partidos não se diferenciavam no eleitorado em termos afetivos. Por outro lado, os sentimentos pelo PT e PDT eram distintos dos sentimentos em relação aos demais partidos, engendrando um outro componente.

Isso denota que, em 2002, os partidos estruturavam os sentimentos dos eleitores entre esses dois componentes partidários: de um lado, PT e PDT, de outro, PSDB, PFL, PMDB e PTB, ou seja, havia nesse contexto, mesmo que de maneira muito tímida, alguma diferenciação dos partidos em termos afetivos. Entretanto, em 2006, essa diferenciação deixou de existir. Tal como pode ser observado, apenas um componente fatorial foi extraído, demonstrando a indiferenciação dos partidos.

Tabela 6.1

\begin{tabular}{|c|c|c|c|c|}
\hline & \multicolumn{2}{|c|}{ Tabela 6.1} & & Tabela 6. \\
\hline & \multicolumn{2}{|c|}{2002} & & 2006 \\
\hline & 1 & 2 & & 1 \\
\hline PT & $.0,224$ & 0,816 & PT & 0,456 \\
\hline PDT & 0,287 & 0,790 & PDT & 0,891 \\
\hline PSDB & 0,783 & 0,014 & PSDB & 0,792 \\
\hline PFL & 0,727 & 0,033 & PFL & 0,889 \\
\hline PMDB & 0,741 & $-0,005$ & PMDB & 0,850 \\
\hline PTB & 0,611 & 0,456 & PTB & 0,909 \\
\hline
\end{tabular}

Fonte: ESEB, 2002 e 2006.

Apesar dessa não-diferenciação dos partidos, nota-se que o PT não pertence também ao componente fatorial de 2006 , dado o valor da carga fatorial encontrarse abaixo de 0,5 . Isso significa dizer que apesar de o sentimento dos eleitores pelo PT não se diferenciar suficientemente dos sentimentos pelos demais partidos a ponto de formar um novo componente, esse sentimento também não se igualava ao sentimento por esses demais partidos. Nesse sentido, o PT continuava se diferenciando, mas muito menos do que se diferenciava no contexto eleitoral de 2002.

Para demonstrar essa pequena diferenciação do PT, é interessante realizar outra análise fatorial dos sentimentos pelos partidos, incluindo agora também os sentimentos dos eleitores em relação a algumas lideranças políticas. Da mesma forma que na análise fatorial anterior, para haver diferenciação entre os partidos espera-se que existam tantos componentes fatoriais quantos forem os partidos, requisitados para os eleitores expressarem seus sentimentos. Porém, propõe-se, neste caso, que os sentimentos pelas lideranças políticas estejam no mesmo 
PAIVA, D.; BRAGA, M. S. S.; PIMENTEL JR, J. T. P. Eleitorado e Partidos Políticos no Brasil.

componente de seu partido. A idéia é de que haja uma covariância entre os sentimentos dos eleitores pelos partidos e pelas suas lideranças de forma a demonstrar a congruência desses elementos.

A Tabela 7.1 mostra o conteúdo da análise fatorial dessas variáveis. Observa. se que, em 2002, todos os sentimentos pelos partidos, com exceção de PT e PDT, se encontravam no primeiro componente, assim como os sentimentos por Serra e Fernando Henrique Cardoso, sugerindo que os eleitores que gostavam do PSDB, PFL, PMDB e PTB tendiam a gostar destas duas lideranças. No segundo componente dessa tabela, observa-se a presença dos sentimentos por outras demais lideranças políticas: Leonel Brizola, Paulo Maluf, Jader Barbalho e Antônio Carlos Magalhães, demonstrando que esses não se diferenciavam em termos afetivos nesse contexto.

Já no terceiro componente, observou-se a presença de PT, PDT e Lula. Isso significa dizer que eleitores que gostavam do PT e PDT tendiam a gostar também de Lula e vice-versa. Nesse ponto reside a diferença entre os sentimentos dos eleitores em relação a esses dois partidos: os sentimentos do PDT não formaram um novo componente juntamente com os sentimentos pela sua principal liderança política (Brizola). Ao contrário, os sentimentos pelo PT e por Lula mostraram correspondência, encontrando-se em um mesmo componente.

Tabela 7.1

\begin{tabular}{|c|c|c|c|}
\hline \multirow{2}{*}{ Partidos } & \multicolumn{3}{|c|}{2002} \\
\cline { 2 - 4 } & 1 & 2 & 3 \\
\hline PT & 0,043 & $.0,026$ & 0,586 \\
\hline PDT & 0,237 & 0,236 & 0,702 \\
\hline PSDB & 0,793 & 0,019 & 0,086 \\
\hline PFL & 0,647 & 0,187 & 0,077 \\
\hline PMDB & 0,653 & 0,148 & 0,071 \\
\hline PTB & 0,516 & 0,215 & 0,451 \\
\hline Lula & $-0,271$ & 0,167 & 0,637 \\
\hline José Serra & 0,599 & 0,254 & $.0,182$ \\
\hline Garotinho & 0,164 & 0,473 & 0,251 \\
\hline Ciro Gomes & 0,226 & 0,422 & 0,218 \\
\hline Fernando Henrique & 0,626 & 0,187 & $.0,207$ \\
\hline Brizola & 0,044 & 0,626 & 0,341 \\
\hline Maluf & 0,183 & 0,701 & $.0,114$ \\
\hline Jader Barbalho & 0,123 & 0,746 & 0,004 \\
\hline ACM & 0,145 & 0,621 & 0,072 \\
\hline
\end{tabular}

Fonte: ESEB, 2002 e 2006. 
OPINIÃO PÚBLICA, Campinas, vol. 13, n², Novembro, 2007, p.388-408

Já em 2006, como se verifica na Tabela 7.2, observou-se no primeiro componente fatorial o pertencimento dos sentimentos por todos os partidos, com exceção do PT. O segundo componente fatorial foi formado por todos os sentimentos pelas lideranças políticas, com exceção de Lula. Por fim, no terceiro componente, apareceram os sentimentos por Lula e PT. Lembre-se que na Tabela 6.2 existia apenas um componente fatorial dos sentimentos pelos partidos, entretanto, a Tabela 7.2 mostra que o sentimento pelo PT formou um novo componente à medida em que introduzimos os sentimentos por Lula na análise fatorial. Isso significa dizer que o PT só se diferenciou dos demais partidos na medida em que ele esteve vinculado à figura de Lula, demonstrando sua preponderância em relação ao partido.

Tabela 7.2

\begin{tabular}{|c|c|c|c|}
\hline \multirow{2}{*}{ Partidos } & \multicolumn{3}{|c|}{2006} \\
\cline { 2 - 4 } & 1 & 2 & 3 \\
\hline PT & 0,297 & 0,034 & 0,829 \\
\hline PDT & 0,801 & 0,248 & 0,310 \\
\hline PSDB & 0,825 & 0,242 & $-0,209$ \\
\hline PFL & 0,836 & 0,305 & 0,073 \\
\hline PMDB & 0,815 & 0,232 & 0,108 \\
\hline PTB & 0,844 & 0,263 & 0,197 \\
\hline Lula & 0,060 & 0,065 & 0,882 \\
\hline Geraldo Alckmin & 0,359 & 0,489 & $-0,492$ \\
\hline Heloísa Helena & 0,146 & 0,780 & 0,094 \\
\hline Cristóvam Buarque & 0,355 & 0,751 & 0,126 \\
\hline Aécio Neves & 0,209 & 0,790 & 0,039 \\
\hline José Serra & 0,277 & 0,704 & $-0,181$ \\
\hline
\end{tabular}

Fonte: ESEB, 2002 e 2006. 
PAIVA, D.; BRAGA, M. S. S.; PIMENTEL JR, J. T. P. Eleitorado e Partidos Políticos no Brasil.

Considerações finais

Os dados analisados permitem afirmar que a avaliação satisfatória que os estudos têm feito do desempenho dos partidos políticos brasileiros não pode ser verificada quando esses são analisados no âmbito da representação. No que se refere aos sentimentos partidários, esses já eram pouco significativos em 2002 e tenderam a diminuir em 2006. Isso permite afirmar que os partidos políticos não têm sido bem avaliados por sua clientela. Não é possível afirmar de maneira categórica o quanto esses resultados estão diretamente vinculados às denúncias de corrupção envolvendo lideranças de vários partidos políticos. No entanto, como foi demonstrado, os partidos políticos e o Congresso foram as instituições que receberam as piores avaliações em ambos os surveys aqui analisados. Esse dado reforça a hipótese explicativa mencionada anteriormente.

Outro achado interessante foi a dificuldade do eleitorado de diferenciar os partidos. Se em 2002 era possível observar a clivagem governo X oposição, esta desapareceu em 2006. Se o eleitorado não diferencia os partidos, torna-se difícil o estabelecimento de preferências partidárias minimamente consistentes para balizar a escolha eleitoral.

Na medida em que os partidos políticos são instituições cruciais para o funcionamento da democracia representativa, os laços pouco estáveis entre partidos e o eleitorado aqui verificados e a baixa confiança depositada naqueles levam a ver com preocupação seu impacto a médio prazo para a legimitidade da ordem democrática.

Esses resultados indicam ser necessária uma profícua agenda de pesquisa para verificar as causas desse fenômeno e como essa tendência se articula com a avaliação mais geral do regime democrático e o desempenho de outras instituições. 


\section{Referências Bibliográficas}

ALDRICH, J. H. Why Parties? The origin and transformation of political parties in America. Chicago: University of Chicago Press, 1995.

ALMOND, G. \& VERBA, S. The Civic Culture. Princeton: Princeton University Press, 1963.

BABBIE, E. Métodos de Pesquisa de Survey, Belo Horizonte: Ed. UFMG, 2005.

BOHN, S. e PAIVA, D. "Política estadual e regional e volatilidade eleitoral no Brasil." Paper apresentado no Relatório Final de Pesquisa do Projeto Bases Sócio-Econômicas da Volatilidade Eleitoral no Brasil, Processo No. 401912/2004-3 Edital No. 032/2004, CNPq, 2006.

BRAGA, M. S. S. O Processo Partidário-Eleitoral Brasileiro. Padrões de Competição Política. São Paulo: Humanitas/Fapesp, 2006.

CAMPBELL, A. et al. The American Voter. New York: John Willey, 1960.

CARREIRÃO, Y. de S. A Decisão do voto nas eleições presidenciais brasileiras (de 1989 a 1998). São Paulo: Ed. FGV, 2002.

CARREIRÃO, Y. de S. e KINZO, M. D. G. "Partidos Políticos, Preferência Partidária e Decisão Eleitoral no Brasil (1989-2002)". Dados, vol.47, n.1, 2004.

CASTRO, M. M. M. Determinantes do Comportamento Eleitoral: A centralidade da Sofisticação Política. 1994. Tese de Doutorado, IUPERJ, Rio de Janeiro, 1994.

DALTON, R. J. MACALLISTER, I. \& WATTENBERG, M. "Democracia e Identificação Partidária nas Sociedades Industriais Avançadas”. Análise Social, vol.XXXVIII, Lisboa, 2003.

DIAMOND, L. \& Gunther, R. (eds). Political Parties and Democracy. Baltimore: Johns Hopkins University Press, 2001.

DOWNS. A. An Economic Theory of Democracy. New York: Harper \& Row Publishers, 1957.

ELDERSVELD, S. Political parties in American Society. New York: Basic Books, 1982. 
PAIVA, D.; BRAGA, M. S. S.; PIMENTEL JR, J. T. P. Eleitorado e Partidos Políticos no Brasil.

FIGUEIREDO, M. A decisão do voto. São Paulo: Sumaré, 1991.

FIORINA, M. Retrospective Vote in American National Elections. New Haven: Yale University Press, 1981.

HAIR, Joseph et al. Análise Multivariada de Dados. Ed. Bookman, 2005.

HUNTINGTON. A terceira onda. A democratização no final do século XX. São Paulo: Editora Ática, 1991.

KINZO. Oposição e Autoritarismo: gênese e trajetória do MDB 1966-1979. São Paulo: Vértice, 1998.

M. D. G. "Os Partidos no Eleitorado: percepções públicas e laços partidários no Brasil.” RBCS, Vol. 20, n. 57, 2005.

LAMOUNIER, B. O "Brasil autoritário" revisitado: o impacto das eleições sobre a abertura. In: STEPAN, A. (org.). Democratizando o Brasil. Rio de Janeiro: Paz e Terra, 1988.

LA PALOMBARA, J. e WEINER, M. The origin and development of political parties. In: LA PALOMBARA, J. \& WEINER, M. (eds.). Political Parties and Political Development. Princeton: Princeton University Press, 1966.

LIMONGI, F. e FIGUEIREDO, A. Executivo e Legislativo na Nova Ordem Constitucional. Rio de Janeiro: Ed. FGV, 1999.

"Incentivos Eleitorais, Partidos e Política Orçamentária." Rio de Janeiro, Dados, vol.45, n.02, p. 303-344, 2002.

LIPSET, S. M. The americanization of european left. In: DIAMOND, L. \& GUNTHER, R. (eds). Political Parties and Democracy. Baltimore: Johns Hopkins University Press, 2001.

MAINWARING, S. Rethinking Party System in the Third Wave of Democratization: The case of Brazil. Stanford: Stanford University Press, 1999.

MAINWARING, S. \& TORCAL, M. "Party System Institutionalization and party system theory after the Third Wave of Democratization." Kellog Institute: Working Papers. n.319, 2005. Disponível em: <http://kellogg.nd.edu/publications/workingpapers/WP311 320.shtml> 
OPINIÃO PÚBLICA, Campinas, vol. 13, n², Novembro, 2007, p.388-408

MENEGUELLO, R. Partidos e Governos no Brasil Contemporâneo (1985-1997). 01ªed. São Paulo: Paz e Terra, 1998.

NICOLAU, J. M. Multipartidarismo e Democracia. Rio de Janeiro: Ed. FGV, 1996.

PAIVA, D e BOHN, S. "Sistema Partidário e Volatilidade Eleitoral no Brasil (1982-2006): um estudo sobre a dinâmica inter-regional." Paper apresentado no 31. Encontro da anual ANPOCS, 2007.

PEREIRA, J. C. R. Análise de Dados Qualitativos. São Paulo: EDUSP, 2004.

PIMENTEL JR., J. Disposições Afetivas e Laços Partidários. In: KINZO, M. D. e BRAGA, M. S (orgs.). Eleitores e Representação Partidária no Brasil. Humanitas-Fapesp. 2007, (no prelo).

POPKIN, S. The reasoning voter. Chicago: University of Chicago Press, 1991.

REIS, F. W. Os partidos e o regime. São Paulo: Símbolo, 1978.

SARTORI, G. Partidos e sistemas Partidários. Brasília: Ed.UnB, 1982.

SCHMITTER, P. C. Parties are not what they once were. In: DIAMOND, L. \& GUNTHER, R. (eds.). Political Parties and Democracy. Baltimore: Johns Hopkins University Press, 2001. 